\title{
INSTITUCIONALIZAÇÃO DE PRÁTICAS E POLÍTICAS DE CONCESSÃO DE CRÉDITO E DE COBRANÇA EM UMA EMPRESA DO RAMO DE NUTRIÇÃO ANIMAL
}

Joelma Sandra da Silva ${ }^{1}$

Suzane Bento Brandão ${ }^{2}$

Jose Luiz Borsatto Junior ${ }^{3}$

SILVA, J. S. da; BRANDÃO, S. B.; BORSATO JUNIOR, J. L. Institucionalização de práticas e políticas de concessão de crédito e de cobrança em uma empresa do ramo de nutrição animal. Revista de Ciências Empresariais da UNIPAR, Umuarama, v. 22, n. 1, p. 15-42, jan./jun. 2021.

RESUMO: Este estudo objetivou compreender como ocorreu o processo de institucionalização dessas novas práticas e políticas de concessão de crédito e cobrança. Para tal finalidade, investigou-se uma indústria paranaense, à luz da Teoria Institucional. A empresa em questão passou recentemente por um processo significativo de mudanças em seu departamento financeiro. Adotouse abordagem qualitativa de pesquisa, e a coleta de dados foi realizada por meio de entrevistas e pesquisa documental. Adotaram-se como procedimentos analíticos a análise de conteúdo temática e as codificações aberta, axial e seletiva. Constatou-se que a empresa enfrentou uma mudança organizacional que ocorreu devido à desinstucionalização de práticas e políticas que se mostraram ineficientes, visto que a empresa possuía um grande volume de valores a receber e passava por dificuldades financeiras. A nova postura dos sócios dos gestores e dos funcionários da organização provocaram a institucionalização de novas políticas de concessão de crédito e de cobrança, o que reestabeleceu a saúde financeira da empresa e aprimorou as relações com os clientes. Conclui-se que essa mudança organizacional proporcionou o aperfeiçoamento das práticas e políticas de concessão de crédito e cobrança, dos índices de inadimplência, da inter-relação entre os indivíduos envolvidos no processo. Ainda, impulsionou a sofisticação do departamento financeiro da empresa.

PALAVRAS-CHAVE: Concessão de crédito; Políticas de cobrança; Velha Economia Institucional; Contabilidade Gerencial; Mudança organizacional.

DOI: https://doi.org/10.25110/receu.v22i1.8437

${ }^{1}$ MBA em Controladoria, Gestão Financeira e Auditoria pela UNIPAR. joelmasilvachequim@gmail. com

${ }^{2}$ MBA em Controladoria, Gestão Financeira e Auditoria pela UNIPAR. suzanebb2049@gmail.com ${ }^{3}$ Mestre em Contabilidade pela UNIOESTE. Professor Adjunto da Universidade Paranaense UNIPAR.joseborsatto@prof.unipar.br 


\section{INSTITUTIONALIZATION OF CREDIT AND COLLECTION POLICIES AND PRACTICES IN AN ANIMAL NUTRITION COMPANY}

ABSTRACT: This study aimed at understanding how the process of institutionalizing the new practices and policies for granting credit and collection took place. For this purpose, an industry from Paraná was investigated in the light of Institutional Theory. The company in question has recently undergone significant changes in its finance department. A qualitative research approach was adopted, and data collection was carried out through interviews and documentary research. Thematic content analysis and open, axial, and selective coding were adopted as analytical procedures. It was found that the company faced an organizational change that occurred due to the deinstitutionalization of practices and policies that proved to be inefficient, since the company had a large volume of values receivable and was experiencing financial difficulties. The new attitude of the managing partners and employees of the organization led to the institutionalization of new policies and practices for granting credit and collection, which reestablished the financial health of the company and improved relationships with customers. It can be concluded that this organizational change provided the improvement of credit granting and collection practices and policies, of default rates, of the interrelationship among the individuals involved in the process. It also boosted the sophistication of the company's financial department. KEYWORDS: Credit policies; Collection practices; Old Institutional Economics; Management accounting; Organizational change.

\section{INSTITUCIONALIZACIÓN DE PRÁCTICAS Y POLÍTICAS DE CONCESIÓN DE CRÉDITO Y DE COBRO EN UNA EMPRESA DE NUTRICIÓN ANIMAL}

RESUMEN: Este estudio tuvo como objetivo comprender cómo ocurrió el proceso de institucionalización de esas nuevas prácticas y políticas de concesión de crédito y cobro. Para ello se investigó una industria de Paraná, a la luz de la Teoría Institucional. La empresa en cuestión ha experimentado recientemente cambios significativos en su departamento financiero. Se adoptó un enfoque de investigación cualitativa y la recolección de datos se realizó a través de entrevistas e investigación documental. Se adoptaron como procedimientos analíticos el análisis de contenido temático y la codificación abierta, axial y selectiva. Se constató que la empresa enfrentó un cambio organizacional que se dio debido a la desinstitucionalización de prácticas y políticas que resultaron ineficientes, ya que la empresa tenía un gran volumen de valores a recibir y atravesaba dificultades financieras. La nueva actitud de los socios de los 
directivos y empleados de la organización llevó a la institucionalización de nuevas políticas de concesión de crédito y cobranza, lo que restableció la salud financiera de la empresa y mejoraron las relaciones con los clientes. Se concluye que este cambio organizacional propició la mejora de las prácticas y políticas de otorgamiento de crédito y cobranza, de las tasas de morosidad, de la interrelación entre las personas involucradas en el proceso. También impulsó la sofisticación del departamento financiero de la empresa.

PALABRAS CLAVE: Concesión de crédito; Políticas de facturación; Economía institucional antigua; Contabilidad Gerencial; Cambio organizacional.

\section{INTRODUÇÃO}

Cada vez mais as organizações buscam criar mecanismos de contabilidade gerencial capazes de promover a redução de custos, melhorar rentabilidade e otimizar o desempenho. Porém, conforme Guerreiro, Frezatti, Lopes e Pereira (2005), a questão da relevância da contabilidade gerencial, diante da crescente competição global e mudanças revolucionárias na gestão operacional das empresas, vem sendo questionada há décadas.

A demanda por controles eficientes que possam auxiliar os gestores na tomada de decisão tem crescido acentuadamente, juntamente com a alta competitividade entre organizações. Ademais, os gestores demandam informações gerenciais específicas para suportar suas necessidades de tomada de decisões em ambiente de crescente incerteza e para monitorar o progresso no alcance de estratégias (GUERREIRO, et al. 2005). Por exemplo, tornar um produto atrativo envolve questões ligadas ao preço, qualidade, prazo de entrega e pagamento, as quais caminham lado a lado com os sistemas de controles gerenciais (SCG); e esse conjunto possibilita a obtenção de resultados mais eficientes.

Nessa linha de raciocínio, os processos ligados às práticas e às políticas de concessão de crédito e de cobrança também contribuem nesse sentido, pois dessas derivam as regras e procedimentos relativos à concessão de crédito a clientes e a posterior cobrança dos valores a receber. A definição de políticas de concessão de crédito possibilita a minimização do risco inadimplência pelos clientes e impacta o volume de valores a receber. Por outro lado, as políticas de cobrança, permitem incremento nas receitas por meio de vendas a prazo. Tais processos fazem parte da gestão do capital de giro, e são intrínsecos às operações de uma empresa (PADOVEZE, 2012).

De acordo com Lobato, Silva e Ribeiro (2009), ao conceder crédito a seus clientes, a empresa procura analisar aqueles que provavelmente pagarão as dívidas contratadas e os que, eventualmente, deixarão de pagar conforme as condições estabelecidas. A instabilidade da economia e da política nacional tem 
influenciado negativamente nesse controle e na gestão das empresas. Por meio de uma pesquisa realizada pela consultoria especializada em informações de crédito Serasa Experian (2018a, 2018b), sabe-se que o Brasil encerrou o ano de 2017 com 60,4 milhões de inadimplentes em dezembro e com um número recorde de 5,3 milhões de empresas inadimplentes.

Adicionalmente, a retração sofrida pela economia nacional em função da recessão de 2015/2016 provocou diversos desdobramentos na gestão das empresas, principalmente no que concerne à inadimplência, aspecto que impactou diversos segmentos da economia, inclusive na empresa investigada, que buscou minimizar esse impacto, tomando decisões para assegurar a continuidade de suas atividades.

Scapens (2006) afirma que é evidente que existam grandes tendências econômicas, sociais e organizacionais que afetam a forma como as empresas e suas práticas individuais emergem. No caso da empresa investigada, ocorreu a adoção de novas práticas e políticas de concessão de crédito e de cobrança que promoveram mudanças na área responsável por tais atividades, buscando-se a redução da inadimplência. Consequentemente, a institucionalização dessas novas práticas e políticas promoveu mudança nas práticas contábeis, organizacionais e políticas financeiras outrora vigentes na empresa.

A partir da problematização apresentada e à luz da teoria institucional, tem-se a seguinte questão de pesquisa: como as novas práticas e políticas de concessão de crédito e de cobrança se institucionalizaram em uma empresa do ramo de nutrição animal? Considerando-se que a empresa objeto de estudo passou por um processo de mudança organizacional, o presente estudo objetivou compreender como ocorreu o processo de institucionalização dessas novas práticas e políticas de concessão de crédito e cobrança. Para se atingir o objetivo geral, definiram-se os seguintes objetivos específicos: a) identificar as práticas e políticas de concessão de crédito e cobrança anteriores à mudança organizacional; b) identificar as práticas e políticas de concessão de crédito e cobrança atualmente desempenhadas pela organização; c) compreender como as novas práticas e políticas de concessão de crédito e cobrança se institucionalizaram.

O enfoque institucional possibilita a investigação das práticas contábeis, especialmente da contabilidade gerencial, pois torna possível a compreensão da mudança organizacional ocorrida em função da adoção de instrumentos de contabilidade gerencial nas organizações. Assim, o estudo possibilita avanços acerca de uma área específica e pouco explorada em pesquisas, a institucionalização de políticas e práticas de concessão de crédito e de cobrança. Para além da perspectiva teórica, este estudo também contribui para o entendimento das mudanças que ocorrem nos instrumentos contábeis gerenciais, na postura dos gestores e na atuação cotidiana das pessoas que executam realizam 
atividades relacionadas à concessão de crédito e cobrança, assim como o impacto dos resultados dessa área no desempenho organizacional.

Além dessa introdução, o trabalho possui outras quatro seções. A fundamentação teórica aborda a literatura sobre concessão de crédito e cobrança e a sua conexão com a contabilidade e o controle gerencial. Também aborda a teoria institucional, aprofundando-se na Velha Economia Institucional. $\mathrm{Na}$ sequência têm-se o delineamento metodológico, a análise e interpretação dos dados e as considerações finais.

\section{FUNDAMENTAÇÃO TEÓRICA}

\subsection{Políticas de concessão de crédito e cobrança e contabilidade gerencial}

Controlar os recursos financeiros de uma empresa é necessário tanto em tempos de crise, quanto em momentos de crescimento. Na escassez de caixa, o planejamento torna-se primordial para saber as limitações do negócio (LIZOTE; FLORIANI; TAVARES; HERMES, 2017). Ao conceder crédito, as organizações analisam os riscos inerentes a cada operação, e adotam políticas de cobranças eficazes, por meio de controles e políticas internas. $\mathrm{O}$ crédito refere-se à troca de um valor presente por uma promessa de pagamento futuro, incerto devido ao fator de risco (BECKER; SEIBERT; WBATUBA; SALLA, 2016). O risco está ligado ao tipo de operação de crédito, sendo que o prazo tem peso significativo no risco de crédito, pois, à medida que se aumenta o prazo, o futuro torna-se cada vez mais incerto e novos eventos poderão ocorrer e interferir nos rumos da empresa (SILVA, 1988).

As políticas de crédito da instituição credora, a situação financeira dos clientes e eficiência dos serviços de cobrança são fatores determinantes para o recebimento de valores em crédito (IUDÍCIBUS, 2010). Segundo Mendonça e Gonçalves (2002) o objetivo do processo de análise de crédito é o de averiguar a compatibilidade do crédito solicitado com a capacidade financeira do cliente. Deste modo, percebe-se que ao conceder crédito às empresas necessitam de aparatos capazes de auxiliar sua tomada de decisão, que nesse caso é conceder ou não o prazo. A cobrança bem aplicada facilita a relação entre credor e devedor e agiliza o adimplemento, o que garante o retorno do capital investido em valores a receber, condição necessária para a eficiência do ciclo de intermediação financeira (BECKER, et al. 2016)

Nesse contexto, entende-se a relevância da contabilidade gerencial, manifestada por meio de suas práticas, rotinas e controles, para implantar ferramentas voltadas para a tomada de decisão. Em linha com o objetivo deste estudo, a contabilidade gerencial pode ser estudada como um produto de processos institucionais que dão coerência e significado para o comportamento 
da organização (Guerreiro, Frezatti \& Casado, 2006).

De acordo com Guerreiro et al. (2006) a contabilidade gerencial tem a missão de prover informações adequadas para que os tomadores de decisões maximizem o resultado econômico de suas decisões. Miller (1994) introduziu formalmente a perspectiva da contabilidade como prática social e institucional. Se as práticas e rotinas impostas pela Contabilidade Gerencial de fato forem institucionalizadas, podem mudar por completo o cenário e organizacional de uma empresa.

\subsection{Teoria institucional e mudança organizacional}

A teoria institucional é utilizada para a compreensão da contabilidade dentro de um contexto específico, além de mostrar que essa ciência não pode ser analisada como um mero instrumento técnico isolado, deslocada do seu ambiente de atuação. Adiocionalmente, a implantação de novas técnicas contábeis não depende apenas da vontade da organização, mas também da capacidade das pessoas que a ela pertencem, de implantarem as ferramentas à sua rotina de trabalho (FREZATTI; ROCHA; NASCIMENTO; JUNQUEIRA, 2009).

Tal perspectiva teórica, conforme Scapens (2006), possui três vertentes: a Nova Economia Institucional (NIE - New Institutional Economics), a Nova Sociologia Institucional (NIS - New Institutional Sociology) e a Velha Economia Institucional (OIE - Old Institutional Economics). Conforme o autor, a NIE aborda as estruturas usadas para se governar as transações econômicas; a NIS compreende as instituições no ambiente organizacional na formação de estruturas e sistemas organizacionais; e a OIE aborda as instituições que moldam as ações e pensamentos de agentes humanos individuais.

Assim, as pressões externas, econômicas e institucionais, são abordadas nos enfoques da NIE e da NIS, aspectos que se relacionam com a forma como as organizações são estruturadas e regidas. Por outro lado, para se explicar as práticas contábeis de uma organização em particular, não cabe somente o estudo das pressões externas, cada organização interage com o meio externo de modo particular, o que suscita estudos aprofundados e contextualizados à realidades organizacionais específicas. Logo, a OIE permite se observar or ganizações internamente, bem como as instituições que compõem suas práticas (SCAPENS, 2006). Nesse sentido adotou-se para o estudo a perspectiva da OIE, conforme sugerido por Guerreiro et al. (2005).

$\mathrm{Na}$ ótica da OIE, a instituição diz respeito a uma forma e coerência social imposta sobre uma atividade humana, por meio da produção e reprodução de hábitos estabelecidos, pensamentos e ações (BURNS; SCAPENS, 2000). Nesse sentido, na abordagem da OIE o enfoque dos estudos voltam-se para os hábitos formados a partir de rotinas ao indivíduos que desempenham práticas 
sociais (GUERREIRO; PEREIRA; FREZATTI, 2008).

Os hábitos envolvem uma aptidão ou tendência para se empregar formas de ação anteriormente utilizadas, e observa-se que a existência de hábitos não exclui a ideia da intencionalidade do comportamento individual, e não significa que hábitos não possam ser modificados. $\mathrm{O}$ conceito de rotina conecta as ideias de hábito e instituição, em outras palavras, as regras e rotinas se tornam simplesmente a maneira como as coisas são, o que corresponde às instituições (GUERREIRO, et al. 2006).

Os conceitos de hábitos, rotinas e instituições são utilizados para sugerir como as práticas contábeis podem ser caracterizadas como institucionalizadas e começarem a fazer parte do conjunto das pressuposições inquestionáveis da organização (BURNS; SCAPENS, 2000), ou seja, que sejam profundamente instaladas no grupo social e amplamente aceitas, de forma que as pessoas nem cogitam indagar sobre elas.

Burns e Scapens (2000) apresentam uma estrutura conceitual para explicar o processo de institucionalização, conforme ilustrado na Figura 1. O modelo demonstra a ligação entre o campo institucional e o campo da ação. A parte superior do modelo representa o campo institucional e a inferior representa o campo ação, enquanto o centro da figura demonstra de que forma as regras e rotinas interagem entre o campo institucional e o campo de ação.

Figura 1: O processo de Institucionalização

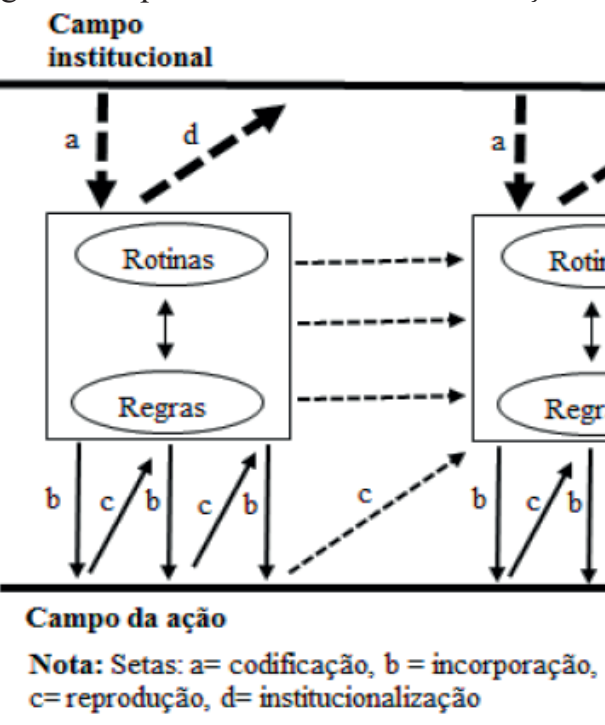

Fonte: Adaptado de Burns e Scapens (2000, p.9). 
Conforme a Figura 1, os autores indicam os estágios do processo de institucionalização: a codificação (a) é o estágio em que o campo institucional codifica princípios em regras e rotinas; na sequência, os atores sociais, com base em suas ações e interações no campo da ação, incorporam (b) as regras e rotinas que codificam os princípios institucionais; o comportamento repetitivo dos atores provoca a reprodução (c) das mesmas; por fim, as rotinas e regras se tornam institucionalizadas (d).

Nesse sentido, a partir das mudanças organizacionais de práticas e políticas de concessão de crédito e cobrança ocorridas na empresa investigada, entende-se que a ótica da OIE é adequada à proposta do estudo, pois esta proporciona um foco em rotinas organizacionais e em sua institucionalização (BURNS; SCAPENS, 2000), o que possilita a compreensão sobre como práticas gerenciais são institucionalizadas.

Outro aspecto pertinente ao estudo envolve a mudança organizacional. Assim como a organizações se transformam ao longo do tempo, as regras e rotinas também se alteram, e algumas mudanças específicas na contabilidade gerencial podem ser bastante revolucionárias, envolvendo mudanças radicais das rotinas existentes e fundamentalmente questionando as instituições existentes (BURNS; SCAPENS, 2000). Os mesmos autores afirmam que os processos de mudanças podem ser divididos em três classes, a saber: mudança formal versus informal, mudança revolucionária versus evolucionária e mudança progressiva versus regressiva.

Rodrigues (2016) detalha acerca desses processos de mudança. A mudança formal ocorre por meio da integração de novas regras ou ações de indivíduos e a mudança informal ocorre à medida que novas rotinas são adaptadas, com o passar do tempo, nas mudanças das condições operacionais. A mudança revolucionária é quando ocorre a interrupção das regras e instituições existentes; e a mudança revolucionária é progressiva, somente com interrupção parcial nas rotinas e instituições. Por fim, a mudança progressiva descreve a substituição do comportamento cerimonial pelo instrumental e a mudança regressiva descreve o comportamentos que reforçam o predomínio cerimonial.

No caso específico deste estudo observou-se uma mudança progressiva em que se instutucionalizou novas atividades relativas à avaliação de crédito e cobrança de clientes.

\section{DELINEAMENTO METODOLÓGICO}

Esta pesquisa caracteriza-se como qualitativa (DEZIN; LINCOLN, 2006). Realizou-se um estudo de caso único conforme a abordagem de Stake (1995), que prioriza um posicionamento intertretativista e a compreensão de 
processos sociais.

O caso analisado é o de uma organização que atua no ramo de nutrição e saúde animal, sociedade limitada, fundada há mais de 30 anos, com sede em uma cidade do interior do estado do Paraná. A empresa é referência no setor em que atua por possuir um mix de diversos produtos com qualidade reconhecida por seus consumidores. Escolheu-se tal caso por se tratar de uma empresa que passou por diversos processos aprimoramento de seus controles gerenciais, especialmente os relativos às práticas das políticas de concessão de crédito e cobrança.

Selecionou-se o departamento financeiro como unidade de análise, e as práticas adotadas para a concessão de crédito, cobrança e gerenciamento desse setor como objeto de estudo. O Quadro 1 apresenta o constructo teórico da pesquisa, o qual foi utilizado para a condução de todo o processo de análise e interpretação de dados.

Quadro 1: Constructo teórico

\begin{tabular}{|c|c|c|c|c|}
\hline \multirow{2}{*}{$\begin{array}{l}\text { Categorias de } \\
\text { análises }\end{array}$} & \multicolumn{2}{|c|}{ Aspectos Investigados } & \multirow[b]{2}{*}{ Autores } & \multirow{2}{*}{$\begin{array}{l}\text { Operacionali- } \\
\text { zação }\end{array}$} \\
\hline & $\begin{array}{c}\text { Definições } \\
\text { Constitutivas }\end{array}$ & $\begin{array}{l}\text { Definições } \\
\text { Operacionais }\end{array}$ & & \\
\hline $\begin{array}{l}\text { Caracterização dos } \\
\text { respondentes. }\end{array}$ & $\begin{array}{l}\text { Funções e } \\
\text { estrutura } \\
\text { organizacional. }\end{array}$ & $\begin{array}{l}\text { Caracterização } \\
\text { da organização } \\
\text { e dos sujeitos de } \\
\text { pesquisa. }\end{array}$ & $\begin{array}{l}\text { Elaborado } \\
\text { pelos autores. }\end{array}$ & $\begin{array}{l}\text { Questões Bloco } \\
1-01 \text { a } 04 .\end{array}$ \\
\hline $\begin{array}{l}\text { Mudança } \\
\text { organizacional. }\end{array}$ & $\begin{array}{l}\text { Mudanças } \\
\text { nas práticas } \\
\text { de concessão } \\
\text { de crédito e } \\
\text { cobrança. }\end{array}$ & $\begin{array}{l}\text { Identificação dos } \\
\text { procedimentos } \\
\text { para a } \\
\text { implementação das } \\
\text { novas práticas. }\end{array}$ & $\begin{array}{l}\text { Dias (2003); } \\
\text { Miranda } \\
\text { e Calmon } \\
\text { (2017); Burns } \\
\text { e Scapens } \\
\text { (2000); } \\
\text { Cardoso } \\
\text { (2005). }\end{array}$ & $\begin{array}{l}\text { Questões Bloco } \\
2-05 \text { a } 09 .\end{array}$ \\
\hline $\begin{array}{l}\text { Campo } \\
\text { institucional } \\
\text { e mudança } \\
\text { organizacional. }\end{array}$ & $\begin{array}{l}\text { Descrição das } \\
\text { políticas de } \\
\text { concessão de } \\
\text { crédito e cobrança } \\
\text { e transição para as } \\
\text { novas práticas. }\end{array}$ & $\begin{array}{l}\text { Investigação das } \\
\text { práticas antigas } \\
\text { de concessão de } \\
\text { crédito e cobrança; } \\
\text { investigação } \\
\text { do processo de } \\
\text { criação novas } \\
\text { práticas. }\end{array}$ & $\begin{array}{l}\text { Russo e } \\
\text { Guerreiro } \\
\text { (2017); } \\
\text { Guerreiro } \\
\text { et.al., (2008); } \\
\text { Scapens } \\
\text { (2006), } \\
\text { Kasznar } \\
\text { (2009), } \\
\text { Mendonça e } \\
\text { Gonçalves } \\
\text { (2002). }\end{array}$ & $\begin{array}{l}\text { Questões } \\
\text { Bloco } 3 \text { - } 10 \text { a } \\
22 \text { e pesquisa } \\
\text { documental. }\end{array}$ \\
\hline
\end{tabular}




\begin{tabular}{|c|c|c|c|c|}
\hline $\begin{array}{l}\text { Instituições } \\
\text { vigentes no } \\
\text { departamento } \\
\text { financeiro }\end{array}$ & $\begin{array}{l}\text { Processo de } \\
\text { institucionalização } \\
\text { das novas práticas } \\
\text { de concessão } \\
\text { de crédito e } \\
\text { cobrança. }\end{array}$ & $\begin{array}{l}\text { Compreensão } \\
\text { do processo das } \\
\text { novas políticas } \\
\text { de concessão de } \\
\text { crédito e cobrança. }\end{array}$ & $\begin{array}{l}\text { Russo e } \\
\text { Guerreiro, } \\
\text { (2017); } \\
\text { Scapens } \\
\text { (2006); Burns } \\
\text { e Scapens } \\
\text { (2000); } \\
\text { Guerreiro et. } \\
\text { al. (2008). }\end{array}$ & $\begin{array}{l}\text { Questões } \\
\text { Bloco } 4 \text { - } 23 \text { a } \\
32 \text { e pesquisa } \\
\text { documental. }\end{array}$ \\
\hline $\begin{array}{l}\text { Campo } \\
\text { sociorganizacional. }\end{array}$ & $\begin{array}{l}\text { Definição dos } \\
\text { indivíduos, } \\
\text { práticas, } \\
\text { tecnologias, } \\
\text { rotinas e recursos } \\
\text { que contribuíram } \\
\text { para geração das } \\
\text { Instituições. }\end{array}$ & $\begin{array}{l}\text { Compreensão } \\
\text { de como os } \\
\text { indivíduos, } \\
\text { práticas, } \\
\text { tecnologias, } \\
\text { rotinas e recursos } \\
\text { contribuíram } \\
\text { para a mudança } \\
\text { organizacional e } \\
\text { institucionalização } \\
\text { das novas políticas } \\
\text { de concessão } \\
\text { de crédito e } \\
\text { cobrança.. }\end{array}$ & $\begin{array}{l}\text { Russo (2015); } \\
\text { Aligleri } \\
\text { e Souza } \\
\text { (2010); Burns } \\
\text { e Scapens } \\
\text { (2000); } \\
\text { Scapens } \\
\text { (2008); } \\
\text { Mendonça e } \\
\text { Gonçalves } \\
\text { (2002); } \\
\text { Frezatti, et. } \\
\text { al., (2009) }\end{array}$ & $\begin{array}{l}\text { Questões } \\
\text { Bloco } 5 \text { - } 33 \text { a } \\
39 \text { e pesquisa } \\
\text { documental. }\end{array}$ \\
\hline
\end{tabular}

Fonte: Elaborado pelos autores.

Criaram-se categorias de análise relacionadas a cada objetivo especifico, conforme a ordem de apresentação de ambos. Para a coleta de dados primários, empregaram-se entrevistas qualitativas semiestruturadas (WARREN, 2002), com base em um roteiro elaborado para se atender aos objetivos da pesquisa. Para a coleta de dados secundários, utilizou-se pesquisa documental. Ressalta-se que a construção do roteiro de entrevista e a definição dos aspectos pertinentes para a análise dos documentos foram fundamentados no constructo teórico.

Quanto aos sujeitos de pesquisa, entrevistaram-se todas as pessoas envolvidas no cotidiano das operações de crédito e cobrança. O Quadro 2 apresenta a caracterização dos indivíduos entrevistados.

Quadro 2: Sujeitos da pesquisa

\begin{tabular}{|l|l|l|l|l|}
\hline $\begin{array}{l}\text { Sujeitos de } \\
\text { pesquisa }\end{array}$ & Função/Cargo & $\begin{array}{l}\text { Tempo de } \\
\text { Atuação no } \\
\text { Cargo Atual }\end{array}$ & $\begin{array}{l}\text { Tempo de } \\
\text { Empresa }\end{array}$ & $\begin{array}{l}\text { Formação } \\
\text { Acadêmica }\end{array}$ \\
\hline Entrevistado 1 & $\begin{array}{l}\text { Assistente } \\
\text { Administrativo }\end{array}$ & 1 ano e 8 meses & 1 ano e 8 meses & $\begin{array}{l}\text { Administração de } \\
\text { Empresas }\end{array}$ \\
\hline Entrevistado 2 & Tesouraria & 6 anos & 14 anos & $\begin{array}{l}\text { Letras e MBA em } \\
\text { Gestão Empresarial }\end{array}$ \\
\hline
\end{tabular}




\begin{tabular}{|c|c|c|c|c|}
\hline Entrevistado 3 & $\begin{array}{l}\text { Gerente } \\
\text { Administrativo/ } \\
\text { Financeiro/ } \\
\text { Contábil }\end{array}$ & 11 anos & 11 anos & Ciências Contábeis \\
\hline
\end{tabular}

Fonte: Elaborado pelos autores.

As entrevistas foram gravadas na íntegra, o que resultou em 2 horas e 25 minutos de gravação. As transcrições das mesmas resultaram em 58 páginas de relatórios no formato: fonte Times New Roman, 12, espaçamento 1,5 cm, todas as margens a $2 \mathrm{~cm}$. A pesquisa documental possibilitou o acesso a relatórios de indicadores de inadimplência dos anos de 2017 e 2018, normas de procedimentos internos, dentre outros, documentos elaborados pelos envolvidos na mudança organizacional da empresa.

Empregaram-se na análise o modelo de Burns e Scapens (2000) e as definições constitutivas e operacionais do constructo da pesquisa. Adotou-se a análise de conteúdo temática (BARDIN, 2016; WALTER; BACH, 2015) e as codificações aberta, axial e seletiva de Denzin e Lincoln (2006) como estratégia de análise de dados. A utilização das categorias de análise possui caráter circular, desse modo a categorização aberta envolveu a criação de códigos a partir da literatura e das categorias de análise definidas no constructo da pesquisa. Além disso, a leitura integral dos documentos e transcrições das entrevistas possibilitaram a criação de outros códicos com base na realidade da empresa investigada. Produziram-se 25 códigos que representam categorias de texto.

A categorização axial envolveu o relacionamento dos códigos que representam categorias de texto com as evidências observadas nos dados analisados. Procedeu-se, nessa etapa, a codificação das evidências empíricos às categorias de texto que remetem à teoria instiducional e à mudança organizacional.

Por fim, na categorização seletiva, estabeleceu-se os significados existentes entre as evidências empíricas codificadas de modo a se atingir o objetivo do estudo. Nesta última etapa executaram-se novas leituras dos dados analisados, recodificações, refinamento das relações entre elementos codificados e a tomada de notas de sentidos compreendidos a partir das abordagens teóricas empregadas nessa investigação. Utilizou-se o software de análise qualitativa Atlas.ti 7.0 como ferramenta de suporte à análise, especialmente para a organização e categorização dos dados.

\section{RESULTADOS E DISCUSSÃO}

Constatou-se a existência de um processo de mudança das práticas e políticas de concessão de crédito e de cobrança, assim como a sua 
institucionalização. Tais processos foram analisados à luz da Velha Economia Institucional, de acordo com a proposta de Burns e Scapens (2000).

Inicialmente, buscou-se entender as características do departamento financeiro da empresa, conforme demonstrado no Quadro 3.

Quadro 3: Campo Organizacional

\begin{tabular}{|c|c|c|}
\hline Características & Trechos/Características & Sujeitos/fonte \\
\hline \multirow{3}{*}{$\begin{array}{l}\text { Departamento } \\
\text { financeiro }\end{array}$} & $\begin{array}{l}\text { "...nós tamos com essa equipe já faz bastante tempo, então } \\
\text { assim é um ambiente gostoso de trabalhar né." }\end{array}$ & Entrevistado 2. \\
\hline & $\begin{array}{l}\text { “... foi implantado as práticas, já foi implantado com as } \\
\text { pessoas que já estavam na empresa há algum tempo. Então já, } \\
\text { então já foi feito com essa equipe contratada anteriormente e } \\
\text { as novas já entram no processo que já tá, já acontece então } \\
\text { elas não vivenciaram o antes né, já entraram no novo, então.” }\end{array}$ & Entrevistado 3. \\
\hline & $\begin{array}{l}\text { “...fizemos algumas mudanças e fizemos mais contratações } \\
\text { que é antigamente era mais terceirizado, é e teve algumas } \\
\text { contratações de funcionários no caso para o setor de vendas } \\
\text { e aí começou a trabalhar mais esse setor, antigamente tava } \\
\text { meio esquecido, então acredito que foi uma união ali né do } \\
\text { nosso trabalho com o comercial que deu esse bons frutos”. }\end{array}$ & Entrevistado 2 \\
\hline
\end{tabular}

Fonte: Dados da pesquisa.

A estrutura organizacional era composta por membros das famílias dos sócios, e ao longo do tempo passou a ser formada por indivíduos com competências e conhecimentos específicos nas áreas de atuação necessárias, conforme demonstra o Quadro 3. O Entrevistado 3 destaca que o departamento financeiro é composto tanto por pessoas com mais tempo de atuação na empresa quanto por pessoas com menor tempo na empresa, sendo que os indivíduos com mais experiência, passaram por todo processo de mudança organizacional. Já os indivíduos com menor tempo de experiência vivenciaram somente a incorporação das novas práticas.

Ademais, ocorreram contratações de novos colaboradores para o departamento comercial, o que contribuiu para a integração entre os departamentos financeiro e comercial (Entrevistado 2, Quadro 3). Como explica Guerreiro et. al., (2006), os indivíduos se sentem participantes do grupo ao qual estão inseridos, colaborando para que ocorra a mudança no campo organizacional.

Conforme a percepção do Entrevistado 2, os indivíduos compartilham a ideia de que o ambiente é harmonioso, e acredita que por esse motivo as pessoas estão pré-dispostas a auxiliarem umas às outras. Esse ambiente de trabalho contribui para que a instituição das novas práticas de políticas de concessão de crédito e cobrança, sejam incorporadas ao processo de mudança, e sejam aceitas de forma inquestionável (BURNS; SCAPENS, 2000). 
Para se compreender o processo que levou a empresa objeto de estudo a reavaliar suas práticas e políticas de concessão de crédito e de cobrança, buscou-se entender a realidade anterior à mudança organizacional por meio da análise dos processos de desinstitucionalização das antigas práticas e políticas e de implementação das novas práticas e políticas de concessão de crédito e cobrança. $\mathrm{O}$ Quadro 4 demonstra as práticas e políticas anteriores à mudança organizacional.

\section{Quadro 4: Práticas e políticas anteriores à mudança organizacional}

\begin{tabular}{|c|c|c|}
\hline Práticas & Trechos/Características & Sujeitos/fonte \\
\hline \multirow{7}{*}{$\begin{array}{l}\text { Políticas de } \\
\text { concessão de } \\
\text { crédito }\end{array}$} & $\begin{array}{l}\text { "...empresa era muito familiar então nós faturávamos um terço } \\
\text { do que fatura hoje, praticamente do faturamento atual era, } \\
\text { não tinha muita política, nenhum tipo de critério. O cara quer } \\
\text { comprar, vende o negócio era mais visto a parte comercial do } \\
\text { que recebimento..." }\end{array}$ & Entrevistado 3 . \\
\hline & $\begin{array}{l}\text { "...igual eu falei, é muitas vezes a gente vê, que o cliente possa } \\
\text { ser um problema, e a gente acaba tapando os olhos, mais aquela } \\
\text { ânsia de vende, de vende, ah ta dando certo até agora né..." }\end{array}$ & Entrevistado 2 \\
\hline & $\begin{array}{l}\text { “...as fichas cadastrais, são um projeto que tem a bastante } \\
\text { tempo já, e a política comercial, política financeira perdão nós } \\
\text { começamos a escreve ela tem uns } 7 \text { anos..." }\end{array}$ & Entrevistado 3 \\
\hline & $\begin{array}{l}\text { “...era só referência, então era tudo por telefone então às vezes } \\
\text { você não conseguia falar com muitas empresas não passam } \\
\text { referencias..." }\end{array}$ & Entrevistado 1 \\
\hline & "...nós não pediamos nenhuma documentação..." & Entrevistado 2 \\
\hline & $\begin{array}{l}\text { "...nossos processos de aprovação de pedido, em } 2016 \text { até } 2016 \\
\text { ele era } 100 \% \text { manual. }\end{array}$ & Entrevistado 3. \\
\hline & $\begin{array}{l}\text { "...e assim acontecia muito, a vai ser a mercadoria pro seu José, } \\
\text { o seu José ta com boleto em atrasado, antigamente saia, a mais } \\
\text { libera pro seu zé que ele vai pagar amanhã..." }\end{array}$ & Entrevistado 3 . \\
\hline \multirow{4}{*}{$\begin{array}{l}\text { Políticas de } \\
\text { cobrança. }\end{array}$} & “...antes era cobrado é semanalmente." & Entrevistado 1 \\
\hline & $\begin{array}{l}\text { "...nós inicialmente quando a gente tinha que cobrar a gente } \\
\text { passava pro comercial uma lista de clientes da carteira do } \\
\text { vendedor que daí seria cobrado nesse momento os vendedores } \\
\text { pediam pra segurar..." }\end{array}$ & Entrevistado 3 . \\
\hline & $\begin{array}{l}\text { “...é não cobra, dá uma segurada no cliente, e com isso a gente } \\
\text { abria-se muito um leque, muito grande é pra não tá cobrando. } \mathrm{E} \\
\text { isso ocasionava um, ocasionava um risco de não recebimento e } \\
\text { muitas vezes a gente perdia, e daí passava muito tempo a gente } \\
\text { não conseguia resgatar." }\end{array}$ & Entrevistado 3 . \\
\hline & $\begin{array}{l}\text { “...não se cobrava um simples juros do cliente, então o cliente } \\
\text { ficava devendo e não cobrava juros, a não vou cobrar multa se } \\
\text { não cliente vai ficar descontente..." }\end{array}$ & Entrevistado 3. \\
\hline
\end{tabular}




\begin{tabular}{|c|c|c|}
\hline \multirow{3}{*}{$\begin{array}{l}\text { Políticas de } \\
\text { cobrança. }\end{array}$} & $\begin{array}{l}\text { "....a gente já tem essa política que num, se o cara atrasou } \\
\text { período de } 90 \text { dias, a gente não vai vender..." }\end{array}$ & Entrevistado 2. \\
\hline & $\begin{array}{l}\text { “...nós não tínhamos muita cultura de protestar cliente, nem } \\
\text { negativar..." }\end{array}$ & Entrevistado 3 . \\
\hline & $\begin{array}{l}\text { “...2015 nós fazíamos em cima do faturamento, então era } \\
\text { meio, então assim a gente não media também. Não media a } \\
\text { inadimplência..." }\end{array}$ & Entrevistado 2. \\
\hline
\end{tabular}

Fonte: Dados da pesquisa.

Percebe-se que a empresa não possuía um critério definido para concessão de crédito aos seus clientes, conforme o Entrevistado 3, o que também é confirmado pelo Entrevistado 2. A organização mantinha um controle de fichas cadastrais, porém sem nenhuma comprovação documental (Entrevistado 2), ou seja, os cadastros eram realizados sem base de confirmação das informações. $\mathrm{E}$ as vendas eram liberadas aos clientes sem nenhum tipo de análise de crédito ou critério preliminar, inclusive eram liberadas a clientes devedores ou inadimplentes. Entende-se que a organização não avaliava de forma correta os riscos de concessão de crédito, pois não existiam subsídios suficientes de informações capazes de fornecer condições para gerenciar o crédito concedido (MAGRO; MONDINI; HEIN, 2015).

Inicialmente a cobrança era realizada pelo próprio departamento comercial, o que ocasionou conflitos de responsabilidades e funções. Isso demonstra que a empresa não possuía uma estrutura organizacional bem definida, nem um modelo de cobrança estabelecido, e o fato do departamento financeiro intervir na cobrança não trazia benefícios, pois os processo de cobrança envolviam a postergação de pagamentos e a comodidade somente dos clientes, como relata o Entrevistado 3.

As cobranças eram realizadas semanalmente, conforme todos os entrevistados (Quadro 4). A empresa possuía uma cultura de não cobrar juros e multas dos clientes inadimplentes, tampouco os protestava ou os negativava, práticas que não condizem com a realidade da maioria das empresas. Também não haviam indicadores de inadimplência que pudessem apontar a ausência de recebimento e estimar as perdas. As medições eram realizadas com base no faturamento e não no recebimento, o que ocasionava uma falta de controle interno, e, eventualmente, em perdas irreversíveis para a empresa.

Entende-se que a empresa possuía um hábito instituído no Departamento Financeiro, como explica Scott (2001). Tais práticas e políticas institucionalizadas foram descontinuadas ao longo do tempo, visto que não eram efetivas, haja vista a ineficiência da concessão de crédito e no controle da inadimplência. $\mathrm{Na}$ percepção do Entrevistado 3, a empresa permitia uma comodidade para o cliente 
em relação as cobranças: "antes, a nossa parte de crédito era, um pouco mais flexível e a parte de cobrança era um pouco mais cômoda para o cliente".

O Entrevistado 3 revelou que um dos fatores que levava a empresa a agir de tal modo, era a insegurança acerca da possibilitade de se perder clientes - consequentemente a venda - em função das cobranças ou de restrições de crédito. Tal postura gerava uma incerteza quanto ao recebimento, ou seja, risco de o tomador do crédito descumprir a obrigação de pagar.

Em consequência dos prazos alongados, limites concedidos e da flexibilidade em relação às práticas de cobrança, e empresa enfrentou dificuldades para liquidar suas próprias obrigações. E em um dado momento foi necessário buscar financiamento em instituições financeiras para se financiar as necessidades de capital de giro da empresa: "quando a gente viu que o negócio apertou mesmo, começou a faltar muito dinheiro, tendo muita conta pra receber, daí a gente se perguntou: 'Pô, mas eu vou pagar juros pro banco?, nós honramos todos nossos compromissos"”. (Entrevistado 3).

A partir dos problemas enfrentados pela organização, fez-se necessário rever todos os controles internos, regras, normas, práticas e políticas voltadas para a concessão de crédito e cobrança existentes. Já não se podia continuar agindo da mesma forma, na percepção dos gestores. Para tanto, Scott (2001) argumenta que a mudança é representada por um processo de desinstitucionalização de estruturas existentes, que representa um processo de enfraquecimento e desaparecimento de instituições. Entende-se a partir desse conceito que, para que novas práticas surjam, outras devem ser extintas, para que ocorra um novo processo de institucionalização (GUERREIRO, et al. 2006).

Nessa esteira, a partir do ano de 2016, introduziram-se novas práticas, políticas e procedimentos no departamento financeiro. Ocorreu a interrupção de regras e procedimentos anteriores, o que caracteriza a mudança revolucionária (BURNS; SCAPENS, 2000). O Quadro 5 demonstra o que foi instituído na organização para que ocorresse tal mudança organizacional. 
Quadro 5: Práticas e políticas posteriores à mudança organizacional.

\begin{tabular}{|c|c|c|}
\hline Práticas & Trechos/Características & $\begin{array}{l}\text { Sujeitos/ } \\
\text { fonte }\end{array}$ \\
\hline \multirow{6}{*}{$\begin{array}{ll}\text { Políticas de } \\
\text { concessão de } \\
\text { crédito }\end{array}$} & $\begin{array}{l}\text { "...a gente utiliza pra análise de crédito: ficha cadastral padrão } \\
\text { da empresa, é pedimos as seis notas fiscais dos últimos meses } \\
\text { de compra do cliente, pra ver se realmente ele tem um potencial } \\
\text { de compra meio similar que compra aqui conosco, consulta no } \\
\text { Serasa e geralmente pro, pro produtor rural só, que é um pouco } \\
\text { mais rígido, não permite tanta, tanta documentação. Na pessoa } \\
\text { jurídica nós pedimos toda parte empresarial CNPJ, CICAD, } \\
\text { contrato social, imposto de renda dos sócios, da empresa, a gente } \\
\text { pede também geralmente o balanço patrimonial em algumas } \\
\text { situações e consulta de SERASA e nós vamos muito pelo nosso, } \\
\text { pelo nosso comercial de campo, a gente pergunta o potencial da } \\
\text { loja, se é uma rede conhecida, então a gente vai mais nessa, na } \\
\text { consulta com o comercial e consulta documental também." }\end{array}$ & $\begin{array}{c}\text { Entrevistado } \\
3 .\end{array}$ \\
\hline & $\begin{array}{l}\text { "...a parte de documentação, ficha cadastral é, eu peço } \\
\text { comprovante de endereço da pessoa física, cópia de RG e CPF, } \\
\text { copias das, de algumas notas fiscais por exemplo onde ele } \\
\text { compra." }\end{array}$ & $\begin{array}{c}\text { Entrevistado } \\
2 .\end{array}$ \\
\hline & $\begin{array}{l}\text { “...ah, é que assim, é tudo bem claro assim, a política existe a } \\
\text { gente tem que seguir e é disseminado para toda a equipe então } \\
\text { assim se chega até mim igual, por exemplo, chega pra mim um } \\
\text { cadastro se ta faltando eu nem passo pra frente, isso eu já falo até } \\
\text { no treinamento, eu falo ó pessoal quando vocês tiverem cadastro } \\
\text { vocês só me mandam quando estiver tudo completo..." }\end{array}$ & $\begin{array}{c}\text { Entrevistado } \\
1 .\end{array}$ \\
\hline & $\begin{array}{l}\text { "...só starta a análise de crédito quando vem tudo, assim ah faltou } \\
\text { o imposto de renda, um RG dos sócios não começa. Daí temos } \\
\text { a (entrevistada 2) que ela faz a primeira validação do cadastro, } \\
\text { é nós temos algumas ferramentas que ela já concede um limite } \\
\text { automático. Automático de forma assim, que ela tem uma Quadro } \\
\text { que já pode ir enquadrando, nos clientes que apresenta um pouco } \\
\text { de dificuldade de crédito, ou que teriam que ter um grande limite } \\
\text { de crédito aí elas conversam comigo." }\end{array}$ & $\begin{array}{c}\text { Entrevistado } \\
3 .\end{array}$ \\
\hline & $\begin{array}{l}\text { "...Hoje praticamente ele é } 90 \% \text { automático, sem intervenção de } \\
\text { usuário então o pedido cai na empresa, se o sistema vai fazer a } \\
\text { leitura de todo o cadastro toda parametrização individual de cada } \\
\text { cliente se não tem nenhuma restrição o próprio sistema já libera } \\
\text { automático financeiro comercial, e já cai pra logística entrega..." }\end{array}$ & $\begin{array}{c}\text { Entrevistado } \\
3 .\end{array}$ \\
\hline & “...é nós não vendemos pra não clientes negativados...” & $\begin{array}{l}\text { Entrevistado } \\
\quad 3 .\end{array}$ \\
\hline $\begin{array}{l}\text { Políticas de } \\
\text { cobrança }\end{array}$ & $\begin{array}{l}\text { "...então assim era um hábito e eu sei que quem chega primeiro } \\
\text { recebe primeiro né, então eu cobro todo dia." }\end{array}$ & $\begin{array}{l}\text { Entrevistado } \\
\quad 1 .\end{array}$ \\
\hline
\end{tabular}




\begin{tabular}{|c|c|c|}
\hline \multirow{5}{*}{$\begin{array}{l}\text { Políticas de } \\
\text { cobrança }\end{array}$} & $\begin{array}{l}\text { “...no dia a dia venceu um boleto é, a essa rotina chega de } \\
\text { manhã, a primeira coisa que faz na parte da manhã e baixar os } \\
\text { borderô, os retorno do banco, baixa no software e já tira uma } \\
\text { relação de clientes, a gente tira uma relação de clientes." }\end{array}$ & $\begin{array}{c}\text { Entrevistado } \\
3 .\end{array}$ \\
\hline & $\begin{array}{l}\text { "....a primeira coisa que eu faço é isso, quanto mais cedo você } \\
\text { manda o boleto pro cliente, mais tempo ele tem para pagar, se } \\
\text { você já, já fiz até o teste se você mandar depois do almoço, não } \\
\text { paga..." }\end{array}$ & $\begin{array}{c}\text { Entrevistado } \\
1 .\end{array}$ \\
\hline & $\begin{array}{l}\text { “...então a gente cobra um juro um pouco alto e uma multa } \\
\text { alta também, então evitou bastante, bastante é perda né de } \\
\text { recebimento nesse sentido também..." }\end{array}$ & $\begin{array}{c}\text { Entrevistado } \\
3 .\end{array}$ \\
\hline & $\begin{array}{l}\text { "...não pagou passou um período de cobrança interno, negativa, } \\
\text { e a gente identificou que... que nós não perdemos praticamente } \\
\text { nenhum cliente, com essa cobrança mais firme, e nem } \\
\text { negativando..." }\end{array}$ & $\begin{array}{c}\text { Entrevistado } \\
3 .\end{array}$ \\
\hline & $\begin{array}{l}\text { “...2016 que a gente começou a fazer em cima do } \\
\text { recebimento..." }\end{array}$ & $\begin{array}{l}\text { Entrevistado } \\
\quad 2 .\end{array}$ \\
\hline
\end{tabular}

Fonte: Dados da pesquisa.

Os controles internos da empresa investigada estabeleceram um conjunto de procedimentos que foram incorporados pelo departamento financeiro ao longo do tempo para que ocorresse a implementação das novas práticas e políticas de concessão de crédito e cobrança. Entretanto, a efetividade dessas práticas políticas está atrelada à capacidade de caracterização dos perfis dos clientes, para a identificação da propensão ao risco de inadimplência (MAGRO; MONDINI; HEIN, 2015).

De acordo com os relatos da coluna "Políticas de concessão de crétido", no Quadro 5, as políticas adotadas pela empresa foram reformuladas conforme as necessidades da organização e em linha com solicitações do departamento financeiro. Aspectos tais como documentação exigida para análise de crédito, análise do perfil de cada cliente, regras para aprovação de crédito são parte da mudança organizacional e contribuíram para a redução da inadimplência descontrolada e concessão de crédito indiscriminada. Essa nova realidade contribuiu sobremaneira para o gerenciamento e para a composição da carteira de clientes da empresa: “...os que saíram, eram clientes que não interessantes para a empresa, que não eram clientes bons, então deu uma selecionada boa na carteira. Com isso essa parte mais rigorosa o próprio comercial começou também ser um pouco mais seleto nos clientes" (Entrevistado 3).

Compreende-se que a empresa estabeleceu uma prática que trouxe mais eficiência para o departamento. E a melhoria da qualidade da carteira de clientes é um reflexo que positivo para as operações e para a gestão de capital de giro da empresa, conforme observado por Lobato, Silva e Ribeiro (2009). Tai 
evidências estão alinhadas ao model ode Burns e Scapens (2000), visot que as novas rotinas passaram pelo processo de codificação, incorporação, reprodução e institucionalização.

Entende-se que a implantação dessas novas práticas e políticas de concessão de crédito evidenciam um processo de institucionalização (BURNS; SCAPENS, 2000). Os indivíduos são influenciados pela empresa e esses mesmos indivíduos influenciam outros indivíduos criando uma dimensão social de mão dupla (GUERREIRO, et al. 2006). A implementação de recursos tecnológicos possibilitou um maior controle do gerenciamento das liberações de pedido de venda, pois a automação auxilia os indivíduos do departamento financeiro no controle de concessão de crédito, no bloqueio de pedidos de vendas para os clientes inadimplentes.

Da mesma forma, as novas práticas e políticas de cobrança foram instituídas. "Quem chega primeiro, recebe primeiro", destacaram os Entrevistados 1 e 3. À vista disso, atualmente a empresa realiza a cobrança diariamente. "já virou um hábito também, eu acho que isso aí foi uma das partes bacanas, que isso virou um hábito, não tem que ter cobrança da gestão sobre a equipe pra cobrar lá ... já virou rotina chegar e fazer as cobranças, então é algo assim que bem, bem tranquilo mesmo" (Entrevistado 3). Com tal afirmação percebe-se a instucionalização da cobrança diária como rotinas, conforme afirmam Guerreiro et al. (2005, p. 99) "as instituições desenvolvem-se pelo processo de rotinização da atividade humana. Dessa forma, as ideias de hábitos e instituições estão conectadas com o conceito de rotinas".

A utilização de recursos como softwares, e-mail, telefone e aplicativos de mensagens permite uma comunicação e uma cobrança mais eficientes, pois isso facilita, como destaca o Entrevistado 2 "esse trabalho diário da cobrança é faz toda a diferença". E também possibilita a abordagem tempestiva aos clientes, tal como explica o entrevistado 3:

"Então nós investimento num software do nosso ERP, que quando é faturado uma nota fiscal automaticamente já manda, cadastra-se um ranking de e-mails que o cliente tem, todos esses e-mails são validados na hora do cadastro e quando a gente implantou essa parte do software foi revisto todos os e-mails do cadastro da empresa inteirinha, pra não ter desculpa de dar algum problema. Então já envia o PDF da nota fiscal, o arquivo XML e o boleto bancário."

Nesse contexto, apreende-se o papel fundamental da utilização de recursos tecnológicos para o aperfeiçoamento dos controles internos, para a mudança organizacional institucionalização das novas práticas e políticas introduzidas no departamento financeiro. 
A eficiência nos recebimentos melhorou da mesma forma, devido às ações dos agentes sociais responsáveis pela cobrança no departamento, principalmente com relação ao momento certo de realinhá-las. Apesar disso, a cobrança é terceirizada em alguns casos: "essa empresa de cobrança eles aceitam títulos até seis meses de vencido, mas assim eu costumo tentar o máximo por aqui né" (Entrevistado 1). Trata-se de uma mudança considerável - e já institucionalizada - em relação ao que era anteriormente praticado. Atualmente, terceirização da cobrança de títulos vencidos a partir de seis meses é uma política que faz parte da rotina do departamento financeiro.

Atualmente, cobram-se juros e multas altos sobre títulos atrasados, o que ameniza a perda com créditos de liquidação duvidosa. E caso o atraso persista após certo prazo, outra política nova diz respeito à negativação do cliente inadimplente nos cadastros de pessoa jurídica e física. Contudo, conforme o Entrevistado 3 (Quadro 5), tais iniciativas não eram tomadas em função do medo de se perder clientela, o que não se concretizou na prática. Apesar das cobranças e nagativações não houve perda significativa de compradores, especialmante aqueles que realizam compras a prazo.

Diante de todas essas novas práticas e políticas de cobrança, entendese que a medida mais positiva para os resultados alcançados foi a adequação do cálculo da inadimplência, o que possibilitou à empresa a obtenção de informações confiáveis para as decisões que se sucederam. Isso porque sem as medidas de desempenho a organização não lidaria de modo eficiente e eficaz com a incerteza inerente ao ambiente de negócios, resultando em utilização deficiente dos recursos e, consequentemente, no aumento da probabilidade de insucesso quanto aos recebimentos (VIEIRA; MAJOR; ROBALO, 2009).

Outro aspecto relevante foi a institucionalização da cooperação entre os depatamentos financeiro e comercial da empresa. Foi perceptível a relação entre os acontecimentos ocorridos no processo de mudança organizacional. As práticas e políticas adotadas para a concessão de crédito promoveram o contexto profíquo de mudança para as práticas e políticas de cobrança, principalmente no que tange os procedimentos de controles internos, o que promoveu a eficácia dos procedimentos da empresa.

Tais resultados positivos permitiram a solidificação da mudança organizacional ocorrida, bem como a sua institucionalização. Segundo Scott (2001), obtêm-se a institucionalização quando os atores organizacionais constroem, de forma racional e eficiente, modelos mentais que possibilitam entender o que é eficiente ou não, de acordo com o compartilhamento de um senso comum de significados com os demais atores envolvidos.

As práticas e as políticas de concessão de crédito e de cobrança da empresa objeto de estudo, passaram por um processo de reestruturação para 
atender as necessidades da organização. A reestruturação foi estimulada devido aos níveis de inadimplência que geraravam perdas à empresa e a inúmeros prejuízos ocasionados pelo modelo de gestão implantado até dado momento. Os sócios e gestores decidiram rever as práticas e políticas até então estabelecidas e conduzidas.

Esse processo de mudança organizacional demandou várias adaptações ao longo do tempo para se alcançar os resultados desejados. Ao longo dos anos as práticas e políticas anteriormente instituídas foram se diluindo nas novas políticas e práticas de conceção de crédito e de cobrança à medida que o tempo foi passando. Para que isso ocorresse, destaca-se a contratação de novas pessoas para os departamentos contectados com essa área e a adoção de novas regras e procedimentos, conforme destaca o Entrevistado 3, “...foi mais por necessidade, nós sentimos a necessidade de documentar todos os processos da empresa, então hoje cada setor, tem $n$ atividades ..., todas são escritas através de "NPIs", que significa normas de procedimentos internos...".

Nota-se que foram estabelecidas NPIs para cada departamento, prática até então inexistente e motivada pelas demandas espefícicas do departamento financeiro. $\mathrm{O}$ que remete a uma mudança de comportamento, envolve também a mudança documental, e ambas são compreendidas como mudanças formais, já que foram definidas pela organização e devem ser executadas. Tais NPIs compõem um aparato de regras e normas, que foram aceitas, incorporadas e reproduzidas pelos indivíduos da organização. Esse aglomerado de hábitos e rotinas reproduzidos pela ação social dos indivíduos envolvidos de forma direta ou indireta, a partir das novas regras, remetem a uma mudança formal, aquela instituída pela organização e aceita e desempenhada pelos indivíduos (BURNS; SCAPENS, 2000).

As normas e práticas ligadas à políticas de concessão de crédito estabeleceram regras para aberturas de cadastros, limites de crédito e liberações de venda, através das documentações essenciais e informações acessórias coletadas ainda in loco, pelos próprios representantes comerciais, e trouxeram mais credibilidade ao departamento fortalecendo o crédito sadio, conforme relata o Entrevistado 2:

“...por exemplo, se é um funcionário externo [recém contratado] vem recebe o treinamento, ele conhece a empresa e tal, e conhece todas as políticas, parte de logística, parte comercial, financeira, todas as políticas da empresa. Hoje nós temos documentos que são internos, que se chama NPI, então todos, todas as regras e normas a gente forma no formato de NPI, então tem, cada departamento tem sua NPI, então o que pertinente a ele [ao departamento] ..." 
Nota-se ainda a ocorrência de mudança informal no departamento financeiro, segundo o Entrevistado 3: “...então isso aí para mim já é um hábito. Para você ter noção, meu relatório eu tiro desde de 2016, todo dia eu tiro da mesma data, de 2016 até hoje...". A cobrança foi implantada informalmente. Devido aos resultados obtidos pelas exigências do departamento de saúde, os demais departamentos aderiram à prática da cobrança diária, pois trazia bons resultados, de uma forma que todos aceitaram, incorporaram e reproduzem no departamento financeiro. Tal cenário remete remete a outra regra imposta informalmente, e que se tornou uma prática institucionalizada pela ação dos indivíduos (BURNS; SCAPENS, 2000).

A implantação de um sistema novo de automação pela empresa também promoveu mudanças significativas, revolucionando as práticas ligadas às políticas de concessão de crédito e cobrança. Como afirma o Entrevistado 2: "nós tivemos uma mudança grande, nós tivemos que implantar todos os cadastros, ... começa tudo de novo, implantar tudo de novo, acho que essa foi a maior mudança que tivemos, ela mexe com todos os departamentos ...". O software otimizou os processos de cobrança, conforme relata o Entrevistado 3:

“...então, assim, é quase que nula a chance de o cara falar que não recebeu, que não recebeu o pagamento. E com cinco dias antes do vencimento o software também já dispara um e-mail automático avisando que o cliente possui um boleto a vencer em cinco dias, e um dia antes do vencimento dispara-se outro e-mail automático; isso não tem nenhuma ação de usuário tudo automático pelo software avisando o cliente que ele tem um boleto que vence no dia seguinte."

Nota-se que tal implantação foi de extrema importância para a que o processo de mudança organizacional ocorresse em todos os níveis da empresa, um investimento facilitou as atividades e a conexão de diversas áreas. Inclusive, melhorou a comunicação entre os colaboradores, por meio do gerenciamento dos cadastros, das concessões de crédito e das cobranças, o que possibilita a mensuração e o acompanhamento dos indicadores de inadimplência. Assim, é possível utilizar tais informações para a projeção de fluxos de caixa e definição de metas para o departamento, o que sinaliza uma mudança revolucionária (BURNS; SCAPENS, 2000).

O Entrevistado 3 contribuiu sobremaneira para a compreensão desse aspecto, visto que tal indivíduo trabalha na empresa há 11 anos, é o gerente financeiro, e participou de todo o processo de mudança organizacional e institucionalização das novas práticas e políticas:

"no mês no dia primeiro e fecha no dia 30 é qual o volume total que eu 
tenho que receber naquele mês, que já está contabilizado. Diante daquele valor nós temos a meta de inadimplência ... Um exemplo do dia primeiro ao dia 30 , tem que receber $\mathrm{R} \$ 100.000,00$. Historicamente nós tínhamos lá que receber $3 \%$ do valor total do mês não entraria. Então é o primeiro analise que nós fizemos, a gente tem fica no primeiro mês em $3 \%$, no segundo mês em torno de $1.5 \%$, e com 90 dias tem que liquidar todo o valor. ... nós temos a meta hoje atualmente de $0,5 \%$ então que a gente trabalha semanalmente, fecha a carteira de a receber. Chegou na segunda feira, analisa o que recebeu na semana anterior e vai vendo na semana o que ficou, e já vai entegrando as cobranças ... [aos] que não pagaram na semana anterior. Fechou o mês, a gente analisa se ficou nos $3 \%$, então tá nos 3\%, nós acreditamos que já está meio dentro da nossa curva. No segundo mês tenta fechar em $1.5 \%$, e no terceiro mês tem que fecha no $0,5 \%$ ".

A empresa estabeleceu uma meta de 3\% de inadimplência sobre os valores a receber, a serem quitados ao longo de um trimestre, e esta mesma meta deveria ser reduzida a uma porcentagem de $0,5 \%$ ao final do terceiro mês. Entende-se que a partir dessa mensuração, a empresa instaurou uma nova regra a ser praticada pela área de cobrança, que por sua vez buscou atingir tal objetivo por meio de cobranças pontuais. Desse modo, criou-se uma rotina que foi totalmente instituída (GUERREIRO, et al. 2006) e incorporada pelo departamento. Assim, a empresa consegue mensurar e avaliar evetivamente o desempenho do departamento financeiro e mantém sobre controle os valores a receber, o que antes não era possível.

A atuações de cobrança foram intensificadas por meio de ferramentas tecnológicas conforme a perspectiva, respectivamente, dos Entrevistados 1 e 2:

“...ou mandando um WhatsApp, ... o [nome do Entrevistado 1] manda muito boleto; às vezes ele nem liga pro cliente, ele já envia o boleto pro cliente por e-mail, já atualizado. Aí as vezes a pessoa já, já verifica e já paga, né?".

“... acho que a mudança foi essa. Antes era cobrado semanalmente e agente passou a cair mais em cima mesmo, da cobrança diária, e por todos os, todas as redes que puder e-mail, telefone, WhatsApp e tudo mais".

A organização ainda utiliza os serviços prestados por uma empresa de cobrança, responsabilizada por cobrar aqueles clientes que comumente não cumprem com os prazos de pagamento e com pendências vencidas há mais de 6 meses. E se nem mesmo a empresa de cobrança conseguir receber os valores em atraso, então a empresa objeto de estudo entra, por fim, com uma ação de execução judicial. 
Antes desse processo de institucionalização, vigoravam políticas que possibilitavam diversas brechas para gerar o aumento da inadimplência, como cadastro incompletos de clientes e não documentados, o que impossibilitava uma análise crédito consistente. A cobrança era descentralizada, realizada geralmente pelo próprio departamento comercial. Não haviam ferramentas capazes de auxiliar o gerenciamento dos cadastros, não existiam limites de crédito definidos, tampouco o bloqueio das vendas para clientes inadimplentes. Os indicadores de níveis de inadimplência não eram fidedignos. Essa conjuntura gerou dificuldades financeiras para a própria empresa. Diante dessa situação os sócios e os gestores decidiram mudar de postura.

Assim, todos os processos internos ligados à concessão de crédito e cobrança foram revistos, especialmente os ligados ao controle. Novas normas e procedimentos internos foram desenvolvidos para todos os departamentos, o que contribuiu, especialmente, para um aumento da eficiência do departamento financeiro, o que está em linha com o modelo de Burns e Scapens (2000). Ainda em linha com os autores, essas normas e procedimentos foram incorporados ao longo do tempo, e desse modo, as novas práticas e políticas se institucionalizaram.

Atualmente o sistema de cadastramento e cobrança é automatizado e conta, também, com recursos tecnológicos para facilitar a comunicação com os clientes e a cobrança. A cobrança passou a ser realizada diária e constantemente, processo que se iniciou informalmente até ser instituído na empresa, em consonância com Burns e Scapens (2000). Todas as pessoas envolvidas de forma direta e indireta com o departamento financeiro receberam treinamentos acerca de novas práticas e políticas instituídas pela organização, o que forneceu condições para que as normas de procedimentos internos fossem compreendidas, executadas, incorporadas, aceitas e disseminadas por todos.

Finalmente, é possível compreender como ocorreu a desinstitucionalização das antigas práticas e políticas de concessão de crédito e cobrança e a institucionalização de novas práticas e políticas. Isso ocorreu ao longo do tempo e diversas etapas de adaptação (BURNS; SCAPENS, 2000), o que promoveu uma mudança organizacional relevante para o desempenho na área financeira da organização.

\section{CONSIDERAÇÕES FINAIS}

O estudo buscou compreender como ocorreu o processo de institucionalização das novas práticas e políticas de concessão de crédito e de cobrança no departamento financeiro de uma empresa do ramo de nutrição animal. Para tanto, realizou-se um estudo de caso com abordagem qualitativa, à luz da abordagem da Velha Economia Instucional. 
Identificaram-se as práticas e políticas de concessão de crédito e cobrança anteriores à mudança organizacional, assim como as novas práticas e políticas na área de crédito e cobrança, ainda em processo de institucionalização, desempenhadas no departamento financeiro da empresa. Constatou-se, também, que algumas adaptações são necessárias, tendo em vista a incorporação dessas pelos clientes.

A empresa objeto de estudo encontra-se na etapa de institucionalização das novas práticas e políticas de concessão de crédito e cobrança, sendo que novas regras e rotinas estabelecidas, incorporadas e reproduzidas, ao ponto de se tornarem instituições. Além disso, a cooperação entre o departamento financeiro e comercial mostrou-se estratégico para o desenvolvimento de novos controles internos e o estabelecimento das políticas e práticas desempenhadas atualmente. Com isso houve a diminuição da inadimplência e melhora no desempenho financeiro da empresa.

Tais mudanças promoveram uma reestruturação no departamento financeiro da empresa, o que refletiu na forma de agir e pensar das pessoas que desempenham as suas funções em tal departamento. Além disso, como a forma de vender a prazo e cobrar mudou, essas mudanças de agir e pensar também se refletiram nos vendedores e nos clientes. Em outras palavras, as novas práticas e políticas percorrem todo o processo de concessão de crédito e posterior cobrança, em que o ponto de partida envolve o cadastro dos clientes e análise da possibilidade de se vender a prazo ou não, e quais as condições dessa venda a prazo, até o momento em que a cobrança ocorre, especialmente quando se trata de títulos vencidos.

Acerca das atuações de cobrança de títulos vencidos, essa etapa envolve um esforço das pessoas do departamento financeiro, as quais contam com recursos tecnológicos para a cobrança automatizada, serviços de cobrança terceirizados, e com o uso dos dispositivos legais para cobrança e protesto dos clientes inadimplentes.

Embora o processo de institucionalização esteja em andamento, salienta-se que os indivíduos são os principais motivadores da mudança e que o desempenho da inadimplência é calculado pelos recursos tecnológicos à disposição da empresa. Porém, cabe salientar que toda essa mudança revolucionária somente foi possível, pois os indivíduos envolvidos no processo estavam pré-dispostos a promoverem a ação no campo institucional.

Como contribuições teóricas, destaca-se que o uso de recursos tecnológicos tais como softwares e aplicativos de mensagens são úteis para a mudança institucional, pois facilitam processos burocráticos e a comunicação entre a empresa e seus clientes. Além disso, o principal motivador da mudança, os problemas financeiros na própria empresa em decorrência dos altos níveis 
de inadimplência do passado, desencadeou uma mudança significativa que culminou em novas práticas e políticas de concessão de crédito e cobrança.

Quanto às contribuições gerenciais, para a empresa investigada, salientase que a compreensão do processo de institucionalização das políticas e práticas atualmente empregadas para a concessão de crédito e cobrança é relevante para que se entenda o peso da falta de controle e acompanhamento sobre certos processos, e de como instrumentos de mensuração e iniciativas ativas podem impactar positivamente no desempenho financeiro da organização.

Nesse sentido, recomenda-se, para estudos futuros, a investigação dos fatores ou eventos que motivam a mudança organizacional e a institucionalização de rotinas, regras e práticas em organizações. Outra sugestão envolve a pesquisa sobre como controles gerenciais, ou ainda instrumentos de contabilidade gerencial se institucionalizam e promovem mudanças organizacionais em áreas específicas da empresa, tais como o setor de crédito e cobrança.

A recomendação final para estudos futuros diz respeito às abordagens da teoria institucional. Empregou-se como delimitação de pesquisa a Velha Economia Institucional, ou seja, uma abordagem estritamente interna em relação à empresa. Desse modo recomenda-se as abordagens da Nova Economia Institucional e da Nova Sociologia Institucional, buscando-se outros enfoques de pesquisa e insights complementares ao contexto interno das organizações.

\section{REFERÊNCIAS}

ALIGLERI, Lilian; SOUZA, Rafael Borim. A contribuição da teoria institucional para a compreensão do modelo de gestão socialmente responsável adotado pelas empresas contemporâneas. Revista Gestão \& Tecnologia, v. 10, n. 2, p. 1-14, 2010 .

BARDIN, Laurence. Análise de conteúdo. São Paulo: Edições 70, 2016.

BECKER, Gisele Patricia; SEIBERT, Rosane Maria; WBATUBA, Berenice Beatriz Rossne; SALLA, Neusa Maria da Costa Gonçalves. Inadimplência empresarial em instituições bancárias: um estudo de caso em cobrança terceirizada. Pensar Contábil, v. 18, n. 66, p. 24-35, 2016.

BURNS, John; SCAPENS, Robert W. Conceptualizing management accounting change: an institutional framework. Management accounting research, v. 11, n. 1, p. 3-25, 2000.

DENZIN, Norman K.; LINCOLN, Yvonna S. O planejamento da pesquisa 
qualitativa: teorias e abordagens. Porto Alegre: Artmed, 2006.

FREZATTI, Fábio; ROCHA, Welington; NASCIMENTO, Artur Roberto. Controle gerencial: uma abordagem da contabilidade gerencial no contexto econômico, comportamental e sociológico. São Paulo: Editora Atlas, 2009.

GUERREIRO, Reinaldo; FREZATTI, Fábio; CASADO, Tânia. Em busca de um melhor entendimento da contabilidade gerencial através da integração de conceitos da psicologia, cultura organizacional e teoria institucional. Revista Contabilidade \& Finanças, v. 17, p. 7-21, 2006.

GUERREIRO, Reinaldo; FREZATTI, Fábio; LOPES, Alexsandro Broedel; PEREIRA, Carlos Alberto. O entendimento da contabilidade gerencial sob a ótica da teoria institucional. Organizações \& Sociedade, v. 12, n. 35, p. 91106, 2005.

GUERREIRO, Reinaldo; PEREIRA, Carlos Alberto; FREZATTI, Fábio. Aplicação do modelo de Burns e Scapens para avaliação do processo de institucionalização da contabilidade gerencial. Organizações \& Sociedade, v. 15, n. 44, p. 45-62, 2008.

IUDICIBUS, Sérgio. Análise de balanços. São Paulo: Editora Atlas, 2010.

KASZNAR, Istvan Karoly. Marketing, políticas de crédito e inadimplência. Vender bem e evitar o mau pagador: um desafio permanente. Revista Pensamento Contemporâneo em Administração, v. 3, n. 2, p. 51-70, 2009.

LIZOTE, Suzete Antionieta; FLORIANI, Izabela; TAVARES, Ketlyn Giliane Schluter; HERMES, Sueli. Uso do fluxo de caixa e sua relação com as dificuldades de permanecer no mercado de pet shops. Revista de Gestão, Finanças e Contabilidade, v. 7, n. 3, 2017.

LOBATO, Fernanda Tavares Rezende; SILVA, Ana Paula; RIBEIRO, Kárem Cristina de Sousa. O impacto da estratégia de crédito na liquidez e rentabilidade: uma análise das lojas de departamentos do setor de comércio varejista. Revista Contemporânea de Contabilidade, v. 6, n. 12, p. 11-34, 2009.

MAGRO, Cristian Baú Dal; MONDINI, Vanessa Edy Dagnoni; HEIN, Nelson. Gestão dos riscos de inadimplência dos tomadores de crédito: um estudo em uma cooperativa de crédito. Pensar Contábil, v. 17, n. 62, p. 55-63, 2015. 
MENDONÇA, J. R.; GONÇALVES, J. C. S. Responsabilidade social nas empresas: uma questão de imagem ou substância? In: ENCONTRO DAANPAD - ASSOCIAÇÃO NACIONAL DOS PROGRAMAS DE PÓS-GRADUAÇÃO EM ADMINISTRAÇÃO, 26, 2002, Salvador. BA, Anais [...]. Rio de Janeiro: ANPAD, 2010.

MILLER, P. Accounting as social and institutional practice: an introduction. In: HOPWOOD, A. G.; MILLER, P. (Eds.). Accounting as social and institutional practice. Grã-Bretanha: Cambridge University Press - Cambridge Studies in Management, 1994, p. 1-39.

PADOVEZE, C. L. Controladoria: estratégica e operacional. São Paulo: Cengage Learning, 2012.

RODRIGUES, S. R. Adoção e implementação de centro de serviços compartilhados sob a óptica da teoria institucional: o caso de um grupo de serviços de tecnologia da informação. 2016. Dissertação (Mestrado em Administração) - Universidade Presbiteriana Mackenzie, São Paulo, 2016.

RUSSO, Paschoal Tadeu; GUERREIRO, Reinaldo. Percepção sobre a sociomaterialidade das práticas de contabilidade gerencial. Revista de Administração de Empresas, v. 57, n. 6, p. 567-584, 2017.

SCAPENS, Robert W. Understanding management accounting practices: a personal journey. The British Accounting Review, v. 38, n. 1, p. 1-30, 2006.

SCOTT, W. R. Institutions and organizations. Thousand Oaks: Sage, 2001.

SERASA EXPERIAN. Inadimplencia tem primeira queda em seis meses aponta Serasa Experian. Sala de Imprensa. 2018a. Disponível em: https:// www.serasaexperian.com.br/sala-de-imprensa/inadimplencia-tem-primeiraqueda-em-seis-meses-aponta-serasa-experian. Acesso em: 13 jan. 2020.

Serasa Experian. Numero de empesas inadimplentes e recorde 53 milhoes em 2017 revela Serasa. Sala de Imprensa. 2018b. Serasa Experian. Disponível em: https://www.serasaexperian.com.br/sala-de-imprensa/numero-de-empresasinadimplentes-e-recorde-53-milhoes-em-2017-revela-serasa. Acesso em: $13 \mathrm{fev}$. 2019.

SILVA, J. P. Análise de crédito: política e decisão de crédito. São Paulo: Atlas, 1988. 
STAKE, R. E. The art of case study research. Londres: Sage, 1995.

VIEIRA, Rui; MAJOR, Maria João; ROBALO, Rui. Investigação qualitativa em contabilidade. In: VIEIRA, Rui; MAJOR, Maria João; ROBALO, Rui.

Contabilidade e controle de gestão: teoria, metodologia e prática, p. 301-331, 2009.

WALTER, Silvana Anita; BACH, Tatiana Marceda. Adeus papel, marca-textos, tesoura ecola: inovando o processo de análise de conteúdo por meio do Atlas.ti. Administração: ensino e pesquisa, v. 16, n. 2, p. 275-308, 2015.

WARREN, C. A. B. Qualitative interviewing. In: GUBRIUM, J. F.;

HOLSTEIN, J. A.; JAMES, A. Handbook of interview research. Londres: Sage, 2002, p. 83-101.

Recebido em: 28/02/2021

Aceito em: 29/03/2021 